\title{
Inguinoscrotal hernia containing the urinary bladder
}

\author{
Kamran Khan, Arif Chaudhry, Marcie B Feinman
}

Department of General Surgery, Sinai Hospital, Baltimore, Maryland, USA

\section{Correspondence to} Kamran Khan, kamkmd92@gmail.com

Accepted 18 August 2016

\section{DESCRIPTION}

A middle-aged patient presented to the emergency department for significant right groin pain. He experienced a 'popping' sensation in the right groin while lifting heavy objects at work 2 days prior. During this time his pain worsened with associated swelling in the ipsilateral testicle and scrotum. He denied fever, nausea, vomiting, diarrhoea or constipation. There was a history of bilateral inguinal hernias, of which only the left side was repaired 2 years ago. The patient had not followed up for the right inguinal hernia; however, it was asymptomatic throughout this time. On admission, vital signs were within normal limits. The patient appeared to be in mild distress due to pain in his right groin. His abdomen was soft, non-tender and non-distended. Genitourinary examination demonstrated significant oedema of the right scrotum with tenderness to light touch. The right testicle appeared inseparable from a mass within the scrotum. The patient did not demonstrate any tenderness at the inguinal ring, with most of his pain located directly over the epididymis. Laboratory studies were within normal limits except for leucocytosis $\left(13.5 \times 10^{3} / \mu \mathrm{L}\right)$. Urinalysis demonstrated occasional bacteria, positive leucocyte esterase and 61 white cell count/hpf. Urine culture grew Escherichia coli $(10-50000 \mathrm{cfu} / \mathrm{mL})$. An ultrasound scan of the testicles demonstrated normal vascular flow without evidence of torsion, with an enlarged right epididymis and varicocele. There was no bowel within the scrotum on ultrasound scanning. A subsequent CT scan of the abdomen with intravenous contrast revealed a right inguinal hernia containing fat and the right anterior corner of the urinary bladder extending into the right hemiscrotum, without the involvement of bowel (figures 1 and 2). A urethral catheter was placed to decompress the bladder and intravenous antibiotics were initiated for epididymitis. The next morning, the patient reported an improvement of his symptoms and was subsequently discharged. He underwent an elective right herniorrhaphy 3 weeks later.

Inguinal bladder hernia (IBH) is an uncommon condition that was first described by Levine in 1951 as scrotal cystocele. ${ }^{1}$ Bladder involvement occurs in 1-4\% of inguinal hernias in the general population and in men above the age of 50 years, this incidence approaches $10 \% .^{1}$ Bladder herniation occurs through an acquired peritoneal defect, classifying it as a direct inguinal hernia and therefore increasing in incidence with age. Most patients are diagnosed incidentally on imaging or at the time of herniorrhaphy due to the sliding nature of these hernias. ${ }^{1}$ IBH can present as intermittent oedema in the groin and urinary tract infection (UTI). ${ }^{1}$ However, bladder incarceration in the inguinal canal and scrotum is possible. Interestingly, in these cases the patient completes urination in a two-stage manner, by initially urinating and then compressing
To cite: Khan $\mathrm{K}$, Chaudhry A, Feinman MB. BMJ Case Rep Published online: [please include Day Month Year] doi:10.1136/ bcr-2016-217408

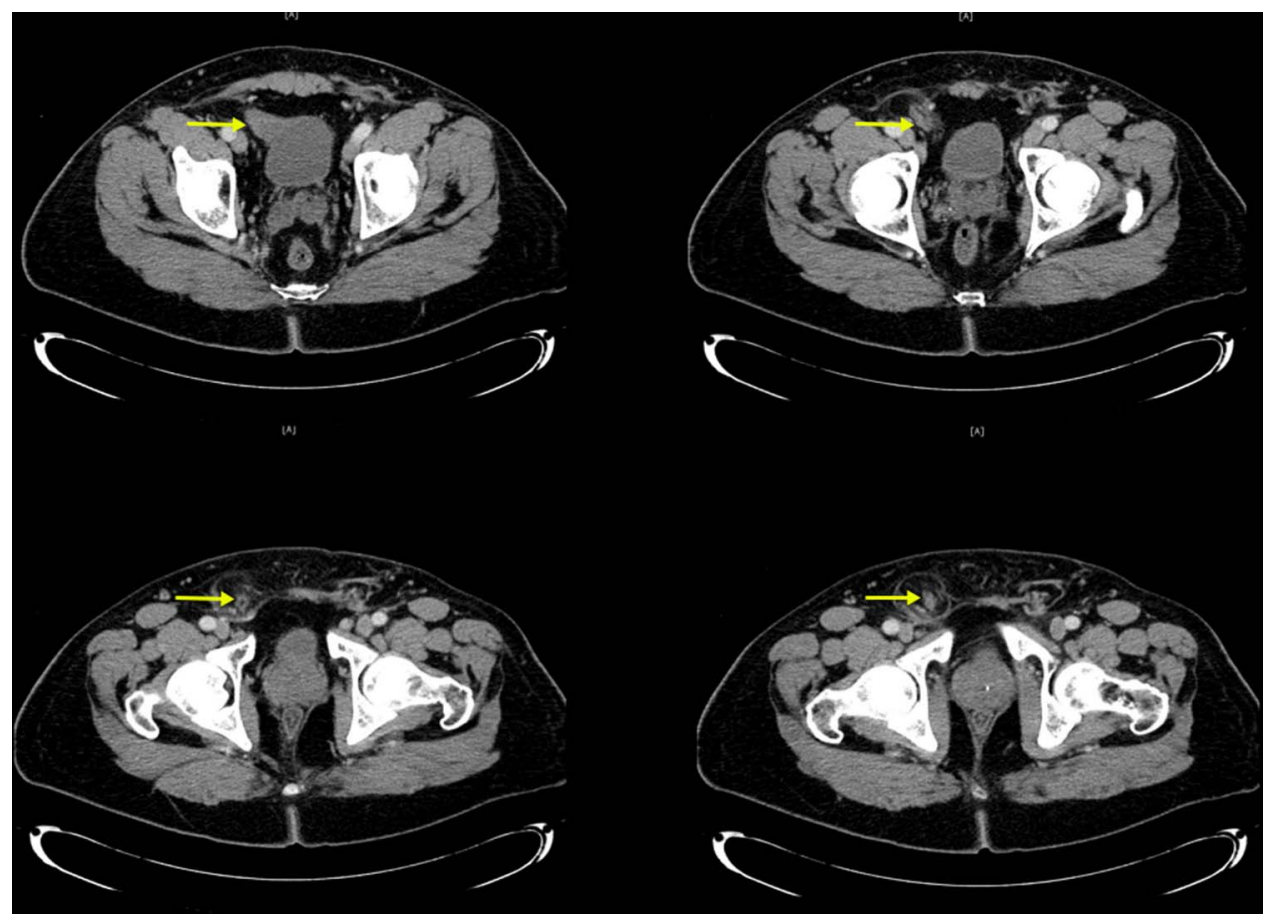

Figure 1 Axial CT scan of the abdomen and pelvis showing the urinary bladder herniating into the right inguinal canal (yellow arrows). 


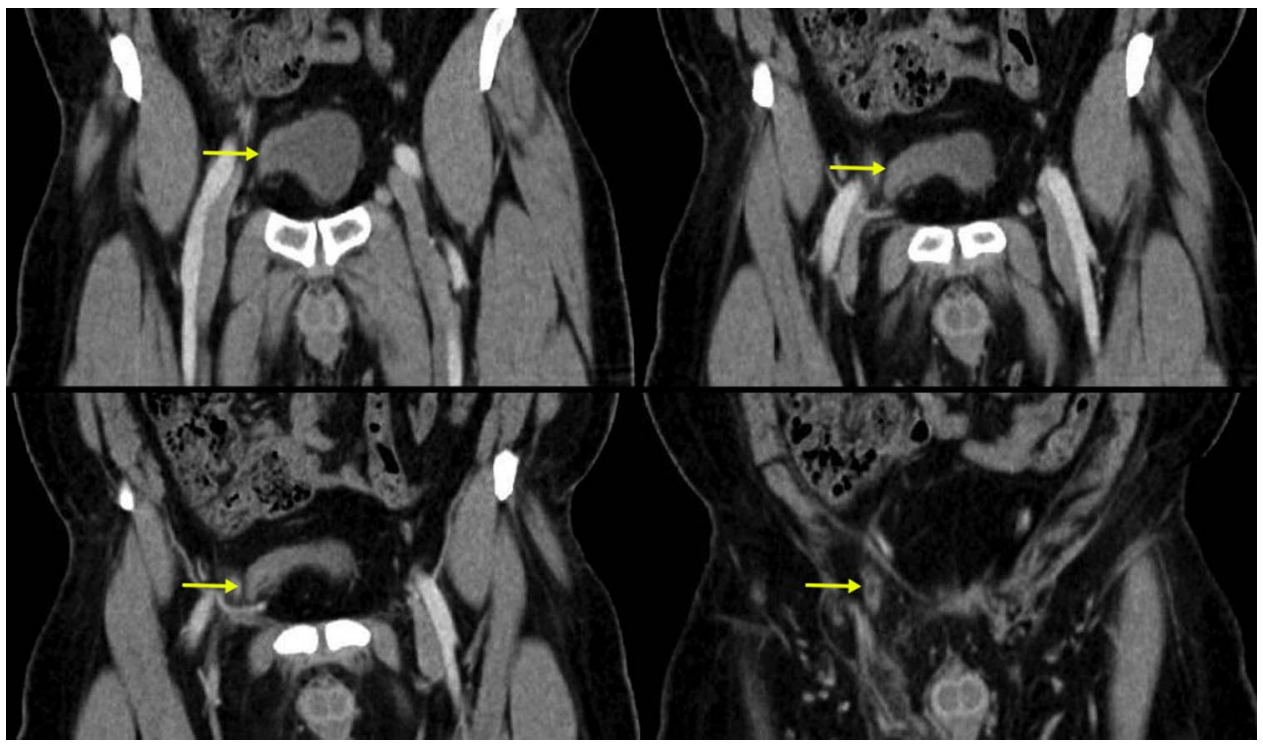

Figure 2 Coronal CT scan of the abdomen and pelvis showing the urinary bladder herniating into the right inguinal canal (yellow arrows).

the scrotum to complete bladder emptying. ${ }^{12}$ Complications include obstructive uropathy, bladder infarction, epididymitis, UTIs and malignancy. A review by Oruç et $a l^{3}$ revealed $11 \%$ (13/116 cases) incidence of genitourinary malignancy in patients

\section{Learning points}

- Bladder involvement occurs in $1-4 \%$ of inguinal hernias in the general population and in up to $10 \%$ in men above the age of 50 years. ${ }^{1}$

- Less than $7 \%$ of inguinal bladder hernias (IBHs) are diagnosed prior to herniorrhaphy, $16 \%$ are diagnosed postoperatively due to complications (bladder injury causing leakage) and the rest are diagnosed intraoperatively. ${ }^{1}$

- A high index of suspicion should be maintained for IBH in high-risk patients, including obese men older than 50 years. In these cases, the contents of the inguinal hernia should be confirmed by CT scan prior to herniorrhaphy. ${ }^{2}$ This can avoid surgical complications including bladder injury, which occurs in $12 \%$ of herniorrhaphies for IBH and allows a modified surgical approach. ${ }^{12}$ with IBH. Less than $7 \%$ of IBHs are diagnosed prior to herniorrhaphy, $16 \%$ are diagnosed postoperatively due to complications (bladder leakage) and the rest are diagnosed intraoperatively. ${ }^{1} \mathrm{~A}$ high index of suspicion should be maintained for IBH in highrisk patients, including obese men older than 50 years. In these cases, the contents of the inguinal hernia should be confirmed by CT scan prior to herniorrhaphy. ${ }^{2}$ This can avoid surgical complications including bladder injury, which occurs in $12 \%$ of herniorrhaphies for IBH and allows a modified surgical approach. ${ }^{1}{ }^{2}$ The treatment for IBH remains the same as any inguinal hernia. During herniorrhaphy, the bladder is identified and reduced to its original location. ${ }^{1}$ Alternatively, patients may be treated conservatively with urethral catheterisation to decompress and reduce the bladder as in this patient.

Competing interests None declared.

Provenance and peer review Not commissioned; externally peer reviewed.

\section{REFERENCES}

1 Kraft KH, Sweeney S, Fink AS, et al. Inguinoscrotal bladder hernias: report of a series and review of the literature. Can Urol Assoc J 2008;2:619-23.

2 Moufid K, Touiti D, Mohamed L. Inguinal bladder hernia: four case analyses. Rev Urol 2013;15:32-6.

3 Oruç MT, Akbulut Z, Ozozan O, et al. Urological findings in inguinal hernias: a case report and review of the literature. Hernia 2004;8:76-9.

Copyright 2016 BMJ Publishing Group. All rights reserved. For permission to reuse any of this content visit http://group.bmj.com/group/rights-licensing/permissions.

BMJ Case Report Fellows may re-use this article for personal use and teaching without any further permission.

Become a Fellow of BMJ Case Reports today and you can:

- Submit as many cases as you like

- Enjoy fast sympathetic peer review and rapid publication of accepted articles

- Access all the published articles

- Re-use any of the published material for personal use and teaching without further permission

For information on Institutional Fellowships contact consortiasales@bmjgroup.com

Visit casereports.bmj.com for more articles like this and to become a Fellow 